\title{
Lactobacillus fermentum MCC2759 and MCC2760 Alleviate Inflammation and Intestinal Function in High-Fat Diet-Fed and Streptozotocin-Induced Diabetic Rats
}

\author{
Ann Catherine Archer ${ }^{1} \cdot$ Serva Peddha Muthukumar ${ }^{2} \cdot$ Prakash Motiram Halami $^{1}$ (D)
}

Accepted: 8 January 2021 / Published online: 11 February 2021

(c) The Author(s) 2021

\begin{abstract}
The growing incidence of type 2 diabetes and obesity has become a worldwide crisis with increased socio-economic burden. Changes in lifestyle and food habits resulting in dysbiosis of the gut microbiota and low-grade inflammation are linked to the rising incidence. The aim of this study was to investigate the effects of potential probiotic Lactobacillus fermentum MCC2759 and MCC2760 on intestinal markers of inflammation using a high-fat diet (HFD)-fed model and a streptozotocin (STZ)-induced diabetic model. Lact. fermentum administration showed improved oral glucose tolerance compared with the model controls of HFD (AUC 1518) and STZ (628.8). Plasma insulin levels improved in the Lact. fermentum treated groups of HFD + MCC2759 $(129 \pm 4.24 \mathrm{pmol} / \mathrm{L})$ and HFD + MCC2760 $(151.5 \pm 9.19 \mathrm{pmol} / \mathrm{L})$ in HFD study, while in STZ diabetic study, the insulin levels were normalized with Lact. fermentum administration, for D + MCC2759 (120.5 \pm 7.77$)$ and $\mathrm{D}+\mathrm{MCC} 2760(138 \pm 5.65 \mathrm{pmol} / \mathrm{L})$ groups. The results showed reduction in inflammatory tone in liver, muscle, and adipose tissues of rats in both models with stimulation of anti-inflammatory IL-10 by real-time quantitative polymerase chain reaction. Additionally, the potential probiotic cultures also displayed normalization of markers related to intestinal barrier integrity (ZO-1), TLR-4 receptor, and insulin sensitivity (GLUT-4, GLP-1, adiponectin). Thus, the results suggest that Lact. fermentum could act as potential probiotic for lifestyle-related disorders such as obesity, diabetes, and metabolic syndrome as both prophylactic and adjunct therapies.
\end{abstract}

Keywords Probiotics $\cdot$ Lactobacillus spp. $\cdot$ IL-10 - GLP-1 - Streptozotocin (STZ)-induced diabetes

\section{Introduction}

Over the previous decades, there is an unabated increase in the incidence of diabetes and obesity worldwide. Diabetes is a multifactorial disease accounting for about $3.5 \%$ of mortality due to non-communicable diseases [1]. The incidence of diabetes is said to increase to 592 million worldwide by 2035 with an estimated high burden of disease prevalence in developing countries. Moreover, most diabetic individuals are obese [2]. Consumption of high-fat foods is a crucial factor for the rise in metabolic diseases and diabetes.

Prakash Motiram Halami

prakashalami@cftri.res.in

1 Microbiology and Fermentation Technology Department, Mysuru, India

2 Department of Biochemistry, CSIR-Central Food Technological Research Institute, 570020 Mysuru, India
Several environmental and genetic factors together with low lying inflammation contribute to the development of insulin resistance coupled with dysbiosis of the gut microbiota leading to the onset of diabetes. This process occurs by host receptors that recognize molecular microbial patterns such as TLRs (toll-like receptors) and NLRs (nucleotide oligomerization domain (NOD)-like receptors) through which bacteria and their components stimulate the immune response [3]. The inflammation is characterized by increased secretion of TNF- $\alpha$ and other pro-inflammatory cytokines which is known to activate protein kinase $\mathrm{C}$ (PKC) leading to enhanced phosphorylation of insulin receptor substrates and its subsequent inactivation, ultimately culminating in insulin resistance [4]. However, the antigens responsible for the induction of inflammation were not known earlier.

The human gastrointestinal tract (GIT) is composed of more than 500 bacterial species, $90 \%$ of which belong to Bacteroidetes (Gram-negative bacteria) and Firmicutes (Gram-positive bacteria). The role of intestinal 
microbiota has recently been implicated in conditions such as gastrointestinal inflammatory disorders, allergies, cardiovascular diseases, cancer, and diabetes [5]. Dysbiosis of the Gram-negative and Gram-positive bacteria ratio increases barrier permeability and translocation of bacterial lipopolysaccharide (LPS). This bacterial translocation is thought to cause metabolic endotoxemia, trigger the mucosal immune response, cause insulin resistance, and eventually diabetes [6]. Diabetic and obese individuals show disturbances in the compositions of Firmicutes, Bacteroidetes, and Proteobacteria. Diabetics are found to have lower counts of Bifidobacterium and Faecalibacterium prausnitzii, both of which are known to possess antiinflammatory properties [7]. Studies of high-fat diet-fed (HFD) animals have shown dysbiosis of the intestinal microbiota coupled by translocation of bacteria from the intestine to other tissues triggering localized inflammation. High-fat feeding also showed an increase in the Gramnegative bacteria to Gram-positive bacteria ratio [3, 7]. Vrieze et al. [8] demonstrated improvement in insulin sensitivity of patients suffering from metabolic syndrome post microbiota administration from lean subjects.

Although lifestyle changes are the primary therapeutic approach for obesity and metabolic syndrome, research for novel therapies targeting the underlying conditions is being probed. Recently, probiotics are known to reduce high-fat diet-induced obesity, diabetes, and metabolic syndrome [9]. Supplementation of probiotics is known to restore the gut microbial balance and modulate the immune response. Probiotics have been suggested as effective adjuvants for the treatment of insulin resistance and are explored as therapeutic strategies for the prevention of diabetes onset. Strains of Lactobacillus and Bifidobacterium have shown beneficial effects for glucose equilibrium, hepatic steatosis, and inflammation reduction $[10,11]$. Lactobacilli are also known to possess strong immunomodulatory and anti-inflammatory properties. Hence, the ability of native Lactobacillus cultures to prevent the onset of highfat diet-induced diabetes through immunomodulation needs to be explored.

HFD model depicts characteristics of low-grade inflammation onset, while a high-fat diet along with lowdose streptozotocin (STZ) mimics metabolic characteristics of type 2 diabetes [3, 12]. Probiotic effects are strainspecific. Hence, to obtain a potential probiotic with antiinflammatory activity, we screened several fermented dairy products and infant faecal samples and selected two strains of Lact. fermentum, MCC2759 (fecal isolate) and MCC2760 (curd isolate). The probiotic properties in vitro in addition to strong adhesion and anti-inflammatory activity in cell line and carrageenan-induced rat model were previously studied [13-15]. In this study, we aimed to study the effects of these two isolates in two models. HFD model will address whether potential probiotics can prevent lifestyle-induced pre-diabetic or diabetic condition via an anti-inflammatory effect. STZ-induced type 2 diabetes model will investigate the therapeutic or adjunct benefits in diabetic conditions.

\section{Materials and Methods}

\section{Bacterial Cultures}

Potential probiotic isolates Lact. fermentum MCC2759 and Lact. fermentum MCC2760 identified in our laboratory were used in this study. Viable count of overnight grown cultures (1.5 OD) was taken by serial dilution and plating on MRS agar. Lact. fermentum MCC2759 and Lact. fermentum MCC 2760 had approximately $10^{9} \mathrm{CFU} / \mathrm{ml}$. The cultures were propagated in MRS medium overnight, and $10^{9} \mathrm{CFU} /$ $\mathrm{ml}$ of cells were suspended in phosphate-buffered saline (PBS) for oral administration in rats.

\section{Animal Maintenance and Diet}

Wistar rats (female) weighing 120-160 g were housed at the institute Animal House Facility, CSIR-Central Food Technological Research Institute, Mysuru. The animals were maintained under controlled temperature and humidity with a 12-h light and dark cycle in standard polypropylene cages. The rats were acclimatized for a week, fed with a normal diet (AIN 93G), and had access to food and water ad libitum. The experimental procedures were followed as per the guidelines of Committee for the Purpose of Control and Supervision of Experiments on Animals (CPCSEA), Government of India, and approved by the Institute Animal Ethical Committee (IAEC), CSIR-CFTRI, Mysuru, following IAEC regulations (Approval no. 335/14).

\section{Study 1: High-Fat Diet Feeding and Grouping}

All animals were fed a normal diet (AIN 93G) for a week before dietary manipulation. Thereafter, normal control rats were fed with a normal diet, while experimental groups received a high-fat diet (Supplementary data 1) for an initial period of 4 weeks. The animals had access to water ad libitum. Subsequently, the rats were divided into the following groups ( $n=6$ rats per group): (1) normal control (NC), (2) high-fat diet control (HFDC), and (3) and (4) high-fat diet-fed groups treated intragastrically with potential probiotic L. fermentum MCC2759 and MCC2760 ( $10^{9} \mathrm{CFU} / \mathrm{ml}$ suspended in PBS) once daily for 4 weeks, respectively. The total duration of the study was 8 weeks. 


\section{Study 2: Induction of Type 2 Diabetes and Grouping}

A total of 40 rats (120-160 g) were taken, control rats were fed a normal diet, while the remaining rats were fed an HFD for 4 weeks as described above. Overnight fasting HFD rats were injected with a single low dose of STZ (Sigma-Aldrich Pvt. Ltd., Bengaluru, India) at $45 \mathrm{mg} / \mathrm{kg}$ body weight dissolved in $0.1 \mathrm{M}$ citrate buffer ( $\mathrm{pH} 4.5$ ) intraperitoneally. Normal or non-diabetic rats $(n=10)$ were administered with only citrate buffer as a vehicle. STZ-induced diabetic rats were given $5 \%$ glucose solution for the first $24 \mathrm{~h}$ to surmount drug-induced hypoglycaemia. Diabetic rats with fasting blood glucose of $>200 \mathrm{mg} / \mathrm{dL}$ were selected 7 days after streptozotocin injection. The rats $(n=10 /$ group) were randomly divided into the following groups: (1) normal control (NC), (2) diabetic control (DC), and (3) and (4) diabetic rats treated with potential probiotic Lact. fermentum MCC2759 and Lact. fermentum MCC2760 $\left(10^{9} \mathrm{CFU} / \mathrm{ml}\right)$ intragastrically for 4 weeks, respectively.

\section{Food Intake, Weight Gain, and Organ Weight}

Food intake and gain in body weight were monitored weekly during the experimental period (4 weeks for type 2 diabetic study and 8 weeks for HFD fed study). The weight of different organs was taken post-necropsy.

\section{Oral Glucose Tolerance Test}

Oral glucose tolerance test (OGTT) was performed after 8 weeks and 4 weeks of study 1 and study 2 , respectively. Rats were starved for 12-14 h before intragastric gavage of glucose (200 g/L in solution; $2 \mathrm{~g} / \mathrm{kg}$ body weight). Blood was taken by pricking the tail vein and measured using a glucometer (Accu-Chek, Roche Diabetes Care India Pvt. Ltd., Mumbai) at 0, 30, 60, and 120 min post glucose administration. Area under curve was calculated from the blood glucose values $(\mathrm{mg} / \mathrm{dL})$ to determine the glucose excursion or tolerance.

\section{Tissue Processing}

Animals were euthanized after 4 weeks of experiment duration. Blood was collected by cardiac puncture and allowed to clot at $4{ }^{\circ} \mathrm{C}$ for $2 \mathrm{~h}$ followed by centrifugation at $757 \mathrm{~g}$-force for $20 \mathrm{~min}$ at $4{ }^{\circ} \mathrm{C}$, and serum was collected. The serum was stored at $-20{ }^{\circ} \mathrm{C}$ until further analysis. Tissues of the intestine, liver, MAT (mesenteric adipose tissue) and muscle were collected and stored in RNA later solution (Sigma-Aldrich Pvt. Ltd., Bengaluru, India) until further use.

\section{Serum Biochemical Analysis}

Levels of glucose, cholesterol, high-density lipoprotein (HDL-C), low-density lipoprotein (LDL-C), triglycerides, cholesterol, total protein, uric acid, urea, creatinine, albumin, SGPT, and SGOT were analyzed in the serum using standard analytical kits (Agappe India Pvt. Ltd., Kerala, India). Plasma insulin was determined using ELISA as per the manufacturer's instructions (Mercodia, Uppsala, Sweden).

\section{Evaluation of Marker Genes by Real-Time qPCR}

Intestine, liver, MAT, and muscle tissues ( $1 \mathrm{~g})$ were homogenized in a tissue homogenizer. The homogenate was subjected to RNA isolation using 1-ml Trizol reagent (SigmaAldrich, Bengaluru, India) according to the manufacturer's instructions. RNA was reversed transcribed into cDNA using Transcriptor High Fidelity cDNA Synthesis Kit (BionovaRoche Chemicals, Bengaluru, India) as per manufacturer's instructions. Real-time quantitative polymerase chain reaction (qPCR) (Biorad CFX-96, Bengaluru, India) was carried out using diluted cDNA (1:25) as a template, SYBR Green Jumpstart Taq ReadyMix (Sigma-Aldrich, Bengaluru, India), and gene-specific primers. The PCR program consisted of an initial denaturation at $94{ }^{\circ} \mathrm{C}$ for 3 min followed by 40 cycles of denaturation $\left(94^{\circ} \mathrm{C}\right.$ for 30 s), annealing $\left(60{ }^{\circ} \mathrm{C}\right.$ for $\left.30 \mathrm{~s}\right)$, and elongation $\left(72{ }^{\circ} \mathrm{C}\right.$ for $30 \mathrm{~s}$ ). Primer specificity and efficiency were evaluated from the melt curves. Data were obtained from triplicate samples run along with no-template control. Oligonucleotide primers were designed using the Primer3 software (http://prime r3.ut.ee/) by obtaining consensus sequences belonging to rat (Rattus norvegicus) genes from NCBI and later synthesized from Eurofins Genomics India Pvt Ltd (Bengaluru, India). The primers related to inflammatory cytokine genes and other markers are listed in Supplementary data 2. Glyceraldehyde 3-phosphate dehydrogenase (GAPDH) gene was used as an endogenous control for normalization of gene expression. Gene expression results were expressed as relative normalized expression (fold change) calculated using the $2^{-} \Delta \Delta \mathrm{Ct}$ method.

\section{Histopathology}

Tissues of liver, kidney, muscle, pancreas, and intestine were sectioned and stained with hematoxylin and eosin (H\&E) stain for histopathology evaluation. The stained tissue slides were observed under a bright-field microscope (Labomed, Burlington, NC, USA). 


\section{Statistical Analysis}

Data were statistically analyzed using GraphPad Prism version 5.00 for Windows (GraphPad Software, San Diego California USA, www.graphpad.com). All data were expressed as mean $\pm \operatorname{SD} / \mathrm{SEM}(n=6)$. One-way ANOVA was used for the analysis of a single parameter, and two-way ANOVA analysis was used for comparison between groups. $p<0.05$ and $p<0.001$ were considered significant for oneway and two-way ANOVA, respectively.

\section{Results}

\section{Food Intake, Weight Gain, and Organ Weight}

Food intake of groups fed with a high-fat diet (study 1) increased significantly compared with the NC group. However, a slight decrease was seen in the groups administered with potential probiotics post 4 weeks of the experiment regimen. Similarly, an increase in body weight was observed in the groups fed a high-fat diet during the initial 4 weeks. However, groups treated with Lact. fermentum gradually showed reduced weight (203 g at 8 th week) as opposed to the high-fat diet control group (225 g at 8th week) which continued to significantly gain weight throughout the experimental duration. Food intake and body weight changes are presented in Supplementary data 3. The weight of organs post-necropsy such as heart, lungs, liver, kidney, intestine, caecum, and stomach showed a substantial increase in the high-fat diet-fed control groups compared with the normal control rats. However, the weight of the organs seemed to be normalized in the groups supplemented with Lact. fermentum MCC2759 and MCC2760 (Table 1).

Diabetes induction resulted in weight loss of the rats compared with the NC group. The bodyweight of Lact. fermentum treated groups did not significantly differ from the DC rats. Diabetes-induced rats also showed typical symptoms of increased urination, increased food, and water intake. There was not much significant difference in the food intake of Lact. fermentum treated groups compared with the diabetic control group ( $30.3 \mathrm{~g} / 24 \mathrm{~h}$ at 4 th week) although it was slightly reduced by the end of 4 th week (25-27 g/24 h at 4th week) (Supplementary data 3). The weight of different organs such as the heart, liver, pancreas, and stomach significantly reduced in diabetic rats compared with normal rats. The weight of the kidney was significantly higher in diabetic rats than the non-diabetic rats (Table 1).

\section{Oral Glucose Tolerance and Plasma Insulin}

OGTT of HFD (study 1) and STZ diabetic study (study 2) after 8 weeks and 4 weeks is depicted in Fig. 1. The data

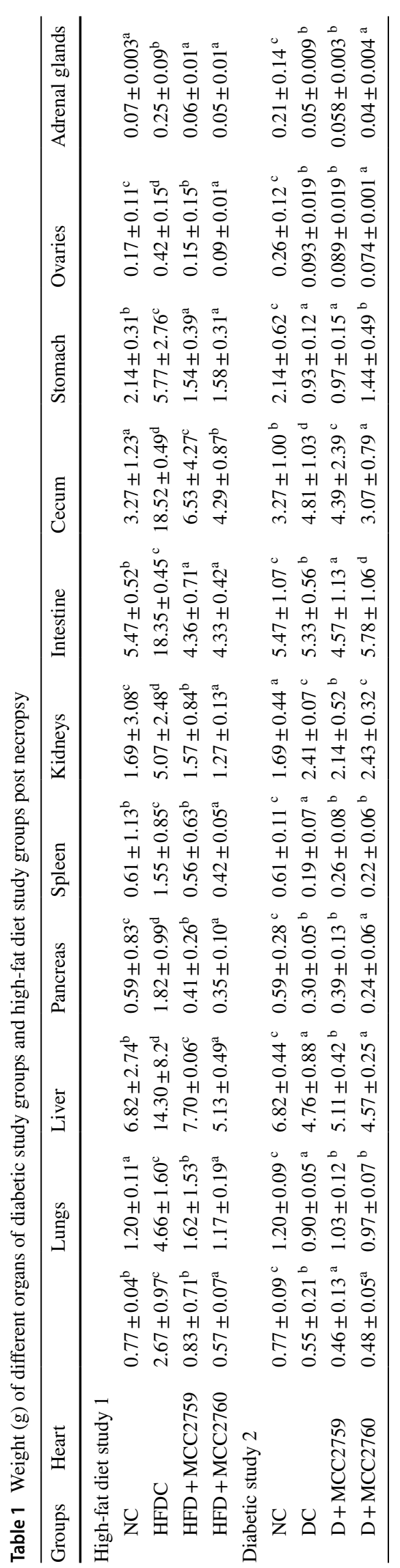


in Fig. $1 \mathrm{a}$ and $\mathrm{b}$ is presented as blood glucose values $(\mathrm{mg} /$ dL) plotted against time post glucose administration. To determine the glucose tolerance, we calculated the AUC, which is widely used as an index for glucose excursion. DC and HFDC groups showed poor glucose tolerance with AUC 628.8 and AUC 1518, respectively. Lact. fermentum treatment groups showed lower AUC values suggesting improved glucose tolerance compared with model control groups in both studies. The AUC of the normal control group was 374.8. Plasma insulin levels in study 1 were $159 \pm 9.89$ and $100.5 \pm 7.77 \mathrm{pmol} / \mathrm{L}$ for the NC and HFDC group, respectively (Fig. 1). The values improved in the Lact. fermentum treated groups of HFD + MCC2759 $(129 \pm 4.24 \mathrm{pmol} / \mathrm{L})$ and HFD + MCC2760 $(151.5 \pm 9.19 \mathrm{pmol} / \mathrm{L})$. In study 2 , the lowest levels of plasma insulin were seen in the DC group $(78.5 \pm 4.94 \mathrm{pmol} / \mathrm{L})$, while the Lact. fermentum treated groups seemed to normalize compared with the NC group with about $120.5 \pm 7.77$ and $138 \pm 5.65 \mathrm{pmol} / \mathrm{L}$ for $\mathrm{D}+\mathrm{MCC} 2759$ and $\mathrm{D}+\mathrm{MCC} 2760$ groups, respectively (Fig. 1).

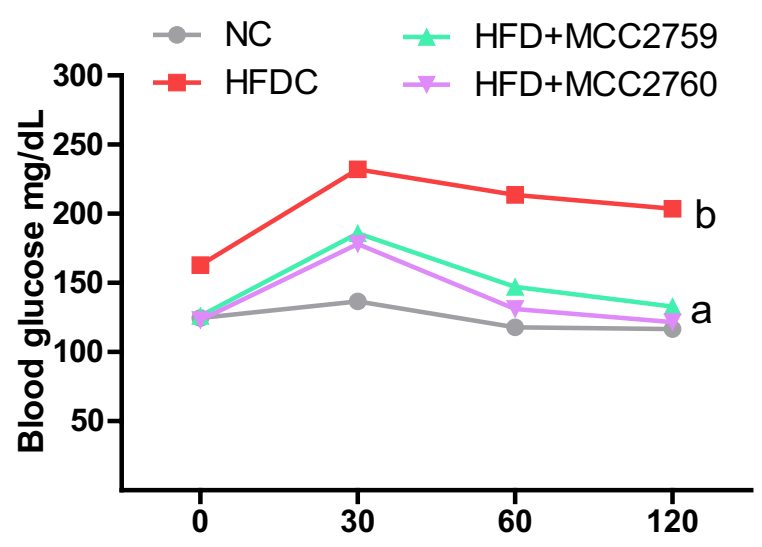

Time post glucose administration (mins)

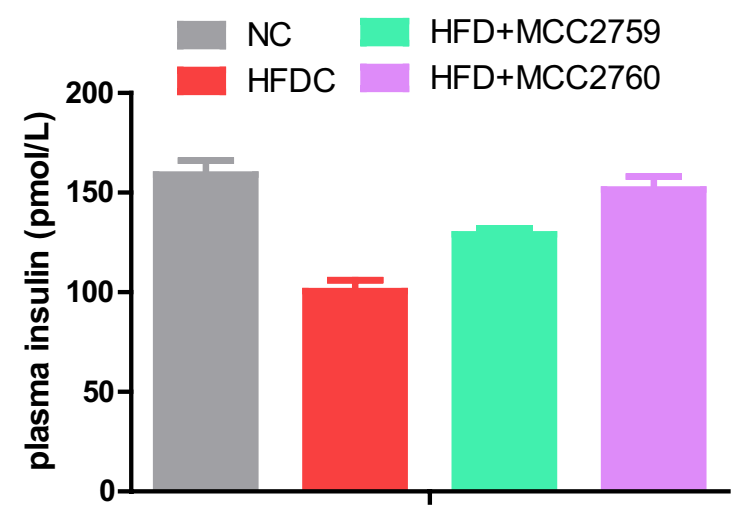

Fig. 1 Effect of potential probiotic administration on $\mathbf{a}$ and $\mathbf{b}$ oral glucose tolerance test and $\mathbf{c}$ and $\mathbf{d}$ plasma insulin (pmol/l) in high-fat diet and STZ-induced diabetic rat groups Data presented as mean \pm SEM

\section{Serum Biochemical Activity}

Serum biochemical analysis was done to evaluate the effect of potential probiotic treatment on biochemical markers (Table 2). In the high-fat diet study 1 , there was an increase in the levels of cholesterol $(126.75 \mathrm{mg} / \mathrm{dL})$, LDL-C (163.17 mg/dL), triglycerides (139.93 mg/dL), and glucose $(160.13 \mathrm{mg} / \mathrm{dL})$ in the high-fat diet control group as a result of fatty diet consumption. However, the levels were normalized significantly in the groups that received potential probiotic bacteria by the end of the experimental period.

In study 2, levels of cholesterol, triglycerides, and LDL-C were significantly lower in the Lact. fermentum treated groups compared with the diabetic control group. Serum glucose levels significantly reduced upon treatment with Lact. fermentum MCC2759 $(367.71 \mathrm{mg} / \mathrm{dL})$ and MCC2760 (201.72 mg/dL) respectively, compared with elevated levels in diabetic control group (436.10 mg/dL).

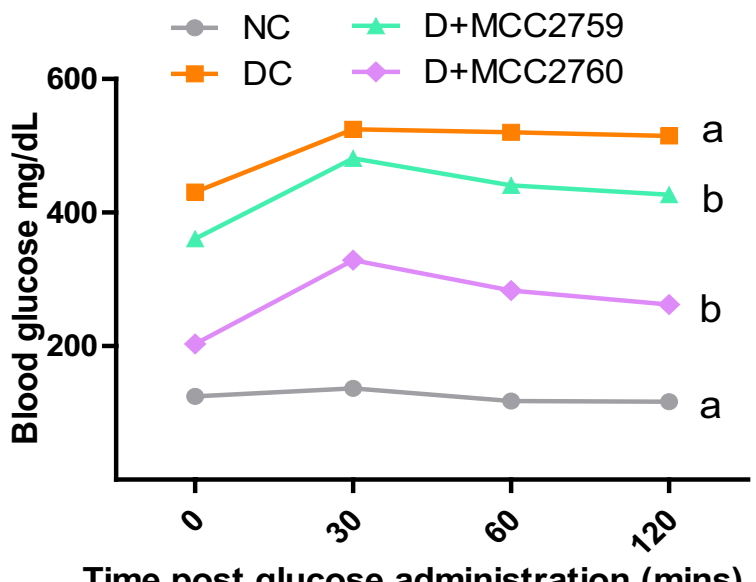

b

C

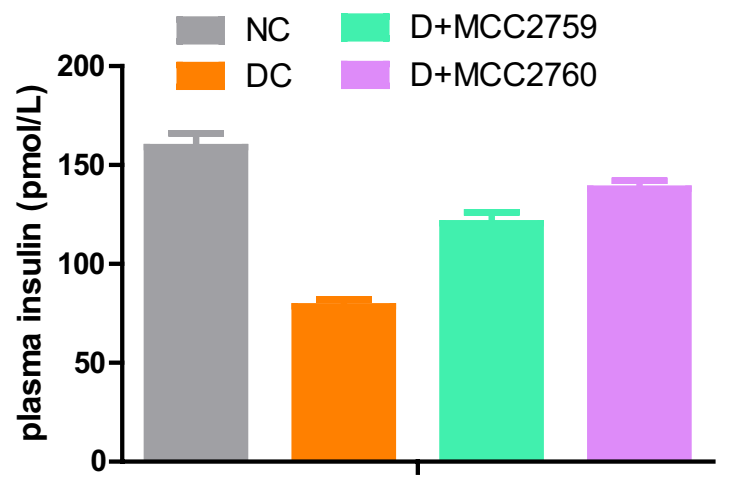

d

$(n=6)$. NC normal control, DC diabetic control, D diabetic, HFDC high-fat diet control, HFD high-fat diet, MCC2759 and MCC2760 L. fermentum spp 
Table 2 Serum biochemical changes of diabetic study groups and high-fat diet study groups

\begin{tabular}{|c|c|c|c|c|c|c|c|c|}
\hline \multirow[t]{3}{*}{ Parameters } & \multirow[t]{3}{*}{ Baseline levels } & \multirow[t]{3}{*}{$\mathrm{NC}$} & \multicolumn{6}{|l|}{ Groups $^{1}$} \\
\hline & & & \multicolumn{3}{|c|}{ High-fat diet-fed study 1} & \multicolumn{3}{|l|}{ Diabetic study 2} \\
\hline & & & HFDC & $\mathrm{HFD}+\mathrm{MCC} 2759$ & $\mathrm{HFD}+\mathrm{MCC} 2760$ & $\overline{\mathrm{DC}}$ & $\mathrm{D}+\mathrm{MCC} 2759$ & $\mathrm{D}+\mathrm{MCC} 2760$ \\
\hline $\begin{array}{l}\mathrm{LDL}(\mathrm{mg} / \\
\mathrm{dL})\end{array}$ & $94.67 \pm 0.39$ & $94.87 \pm 0.05^{\mathrm{a}}$ & $163.17 \pm 10.50^{\mathrm{d}}$ & $154.43 \pm 0.62^{\mathrm{c}}$ & $136.19 \pm 10.50^{\mathrm{b}}$ & $157.63 \pm 7.09^{c}$ & $117.37 \pm 1.16^{\mathrm{b}}$ & $117.04 \pm 1.46^{\mathrm{b}}$ \\
\hline $\begin{array}{l}\mathrm{HDL}(\mathrm{mg} / \\
\mathrm{dL})\end{array}$ & $54.01 \pm 0.18$ & $53.46 \pm 1.34^{\mathrm{a}}$ & $48.63 \pm 3.45^{\mathrm{a}}$ & $50.42 \pm 3.69^{b}$ & $52.52 \pm 7.44^{b}$ & $50.77 \pm 6.09^{\mathrm{a}}$ & $61.51 \pm 3.18^{b}$ & $68.04 \pm 8.37^{\mathrm{c}}$ \\
\hline $\begin{array}{l}\text { Cholesterol } \\
\text { (mg/dL) }\end{array}$ & $62.22 \pm 0.22$ & $63.57 \pm 9.23^{\mathrm{a}}$ & $126.75 \pm 1.69^{d}$ & $84.31 \pm 2.19^{c}$ & $60.62 \pm 3.23^{\mathrm{a}}$ & $90.80 \pm 8.99^{b}$ & $89.34 \pm 2.75^{b}$ & $64.53 \pm 8.99^{\mathrm{a}}$ \\
\hline $\begin{array}{l}\text { Triglycer- } \\
\text { ides (mg/ } \\
\text { dL) }\end{array}$ & $79.95 \pm 0.20$ & $79.38 \pm 2.73^{b}$ & $139.93 \pm 10.91^{\mathrm{d}}$ & $81.44 \pm 0.77^{\mathrm{c}}$ & $54.65 \pm 8.11^{\mathrm{a}}$ & $143.32 \pm 2.7^{\mathrm{d}}$ & $90.18 \pm 3.00^{\mathrm{c}}$ & $68.46 \pm 7.63^{\mathrm{a}}$ \\
\hline $\begin{array}{l}\text { Total } \\
\text { Protein } \\
\text { (g/dL) }\end{array}$ & $7.13 \pm 0.11$ & $6.26 \pm 1.06^{\mathrm{c}}$ & $7.81 \pm 0.18^{\mathrm{c}}$ & $8.95 \pm 0.79^{d}$ & $4.78 \pm 0.22^{\mathrm{a}}$ & $5.95 \pm 0.13^{\mathrm{a}}$ & $6.17 \pm 0.90^{\mathrm{b}}$ & $6.84 \pm 1.29^{d}$ \\
\hline $\begin{array}{l}\text { Uric acid } \\
(\mathrm{mg} / \mathrm{dL})\end{array}$ & $4.18 \pm 0.36$ & $3.64 \pm 0.57^{\mathrm{a}}$ & $2.56 \pm 0.19^{b}$ & $2.48 \pm 1.00^{\mathrm{a}}$ & $3.18 \pm 0.94^{\mathrm{c}}$ & $7.34 \pm 3.80^{\mathrm{b}}$ & $8.88 \pm 6.41^{\mathrm{d}}$ & $8.39 \pm 1.55^{\mathrm{c}}$ \\
\hline $\begin{array}{l}\text { Urea (mg/ } \\
\text { dL) }\end{array}$ & $25.38 \pm 0.11$ & $24.89 \pm 8.40^{\mathrm{a}}$ & $10.96 \pm 1.01^{\mathrm{b}}$ & $10.38 \pm 2.34^{\mathrm{a}}$ & $11.18 \pm 0.42^{\mathrm{c}}$ & $52.05 \pm 1.16^{\mathrm{c}}$ & $40.34 \pm 7.47^{b}$ & $36.20 \pm 7.70^{\mathrm{b}}$ \\
\hline $\begin{array}{r}\text { Creatinine } \\
(\mathrm{mg} / \mathrm{dL})\end{array}$ & $0.84 \pm 0.05$ & $0.61 \pm 1.85^{\mathrm{a}}$ & $0.55 \pm 0.008^{\mathrm{b}}$ & $0.50 \pm 0.04^{\mathrm{a}}$ & $0.56 \pm 0.02^{\mathrm{b}}$ & $1.11 \pm 0.05^{\mathrm{d}}$ & $0.75 \pm 0.01^{\mathrm{b}}$ & $1.18 \pm 0.10^{\mathrm{c}}$ \\
\hline $\begin{array}{l}\text { Glucose } \\
\text { (mg/dL) }\end{array}$ & $119.60 \pm 0.31$ & $121.27 \pm 8.30^{\mathrm{a}}$ & $160.13 \pm 13.51^{\mathrm{c}}$ & $109.05 \pm 6.73^{\mathrm{a}}$ & $105.49 \pm 5.49^{\mathrm{a}}$ & $436.10 \pm 5.88^{d}$ & $367.71 \pm 2.42^{c}$ & $201.72 \pm 5.21^{b}$ \\
\hline $\begin{array}{l}\text { Albumin (g/ } \\
\text { dL) }\end{array}$ & $4.39 \pm 0.18$ & $3.89 \pm 0.71^{\mathrm{c}}$ & $2.40 \pm 0.33^{\mathrm{a}}$ & $3.66 \pm 0.37^{\mathrm{c}}$ & $3.07 \pm 0.58^{b}$ & $3.44 \pm 0.45^{\mathrm{a}}$ & $3.52 \pm 0.12^{\mathrm{b}}$ & $3.51 \pm 0.21^{\mathrm{b}}$ \\
\hline $\begin{array}{l}\text { SGPT } \\
(\mathrm{U} / \mathrm{L})\end{array}$ & $38.83 \pm 0.17$ & $39.59 \pm 0.02^{\mathrm{c}}$ & $26.95 \pm 0.36^{\mathrm{b}}$ & $20.88 \pm 2.40^{\mathrm{a}}$ & $21.23 \pm 3.08^{\mathrm{a}}$ & $18.31 \pm 4.19^{\mathrm{a}}$ & $28.79 \pm 7.15^{\mathrm{b}}$ & $41.17 \pm 1.07^{\mathrm{d}}$ \\
\hline $\begin{array}{l}\text { SGOT } \\
(\mathrm{U} / \mathrm{L})\end{array}$ & $46.05 \pm 0.23$ & $45.56 \pm 0.03^{b}$ & $42.39 \pm 3.06^{\mathrm{b}}$ & $29.68 \pm 0.61^{\mathrm{a}}$ & $42.75 \pm 3.57^{\mathrm{b}}$ & $45.02 \pm 0.04^{\mathrm{b}}$ & $49.89 \pm 0.08^{\mathrm{c}}$ & $39.26 \pm 0.12^{\mathrm{a}}$ \\
\hline
\end{tabular}

${ }^{1}$ Values represented as mean $\pm \mathrm{SD}(n=6)$. Values with different superscripts are significant $(p<0.05)$

${ }^{2} L D L$ low-density lipoprotein cholesterol, $H D L$ high-density lipoprotein cholesterol, SGPT serum glutamate-pyruvate transaminase, $S G O T$ serum glutamic oxaloacetic transaminase, $D$ diabetic, MCC2759 and MCC2760 L. fermentum spp

\section{Effect of Lact. fermentum Administration on Gene Expression}

Relative gene expression of inflammatory markers such as TNF- $\alpha$, IL-1 $\beta$, IL- 6 , and IL-10 in tissues such as intestine, liver, MAT, and muscle are presented in Fig. 2 for study 1 and Fig. 3 for study 2. The expression levels of proinflammatory markers TNF- $\alpha$, IL-1 $\beta$, and IL-6 were elevated in the HFD control group (study 1) and diabetic control group (study 2) in the tissues. However, groups treated with Lact. fermentum showed downregulation of TNF- $\alpha$ while inducing the expression of anti-inflammatory marker IL-10 in both studies. While IL-6 and IL-1 $\beta$ expression was detected in adipose and muscle tissues in study 1 , we were unable to detect the same in study 2 .

Lact. fermentum MCC2759 and MCC2760 treated groups exhibited significant reduced expression of the TLR4 receptor compared with control groups of both studies. Expression of tight junction protein ZO-1, endocannabinoid receptor CB2 and glucagonlike peptide 1 (GLP1) were also increased in the Lact. fermentum treated groups (Figs. 4 and 5). In MAT and muscle tissue, Lact. fermentum treated groups exhibited improved expression of GLUT4 in both studies. Additionally, the expression of adiponectin was upregulated in treatment groups compared with HFD, and STZ-induced diabetic control groups.

\section{Histopathological Observations}

In the high-fat diet-fed study, liver sections stained with hematoxylin and eosin showed cellular infiltration of neutrophils suggesting initial inflammatory response and formation of few vesicular structures indicating the initiation of hepatic steatosis. However, both the inflammatory infiltration and steatosis formation were reversed in the groups treated with Lact. fermentum MCC2759 and MCC2760. Slight disruptions were observed in intestinal sections of high-fat diet-fed rats showing mucosal damage and irregular crypts which were normalized in the Lact. fermentum treated groups while slight glomerular darkening was observed in kidney tissues. 

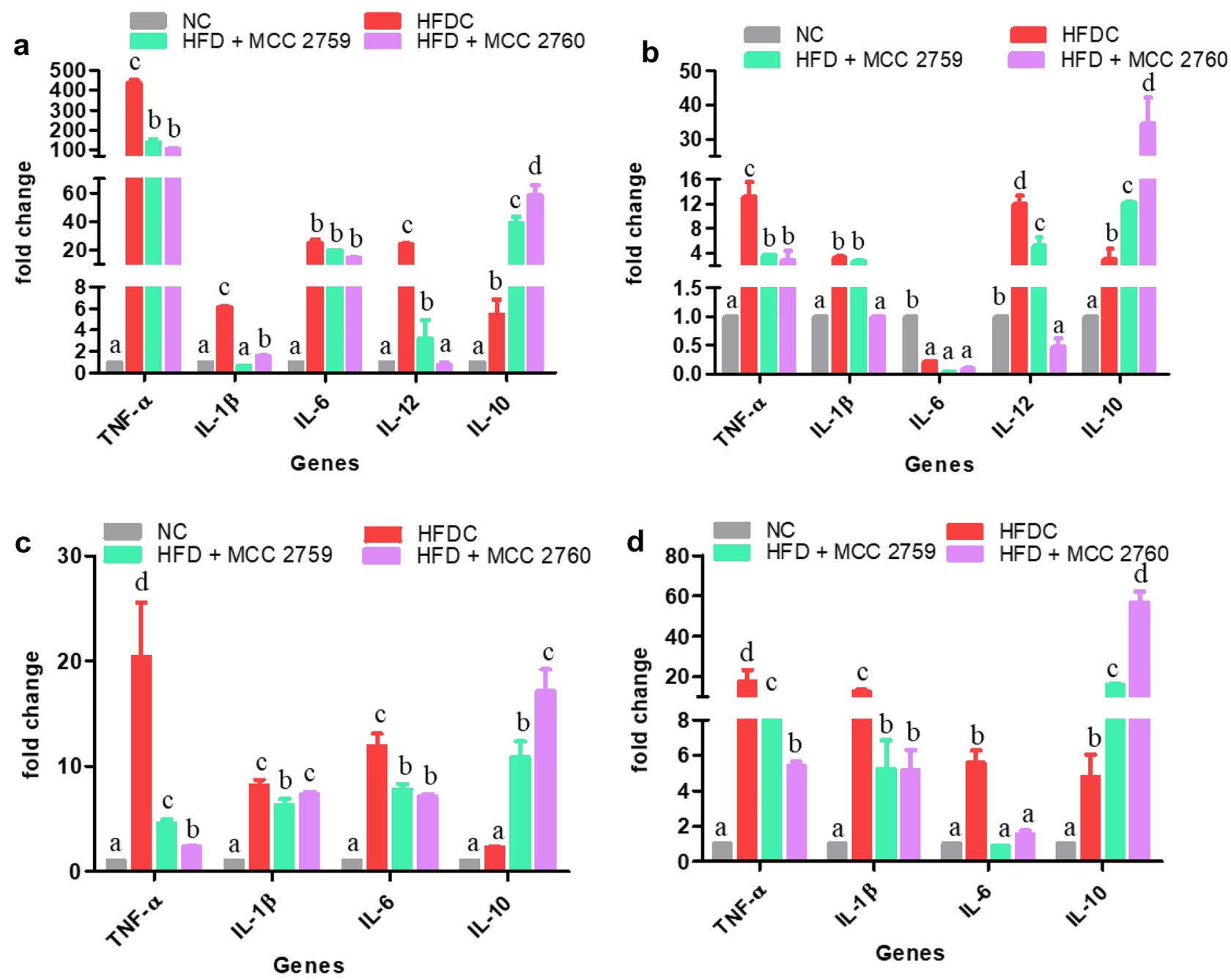

Fig. 2 Expression changes in inflammatory markers of different highfat diet fed study groups monitored by qPCR a intestine, b liver, $\mathbf{c}$ MAT and d muscle tissue; Data presented as mean \pm SEM $(n=6)$. Letters with different superscripts are significant at $p<0.001$. The

Liver micrographs of diabetic study rats showed reduced inflammation in the Lact. fermentum treated groups compared with the diabetic control group which showed accumulation of neutrophils around the portal tracts. Kidney sections showed a reduction in the glomerular injury of diabetic rats characterized by darkened Bowman's capsule and thickening of the capsule after treatment with Lact. fermentum spp. Diabetic rats also showed disruptions in the intestinal structure showing damage of mucosa, crypts, and thinning of the muscle lining with shedding. However, Lact. fermentum treatment normalized the integrity of the intestinal mucosa with more goblet cells. Histopathological changes in both models are presented in Fig. 6.
mRNA expression was normalized to GAPDH. NC normal control, HFDC high-fat diet control, HFD high-fat diet, MCC2759 and MCC2760 L. fermentum spp

\section{Discussion}

There is an increasing demand for indigenous probiotic cultures with strain-specific health benefits against various lifestyle diseases. Thus, the isolates Lact. fermentum MCC2759 (infant faecal isolate) and Lact. fermentum MCC2760 (dairy isolate) were selected based on their potential probiotic properties and antiinflammatory activity [13-15]. In this study, we evaluated the efficacy of these two isolates in alleviating the effects of HFD-induced pre-diabetic inflammatory condition as well as the effects of type 2 diabetes. High-fat diet fed for three or more weeks is said to induce insulin resistance 

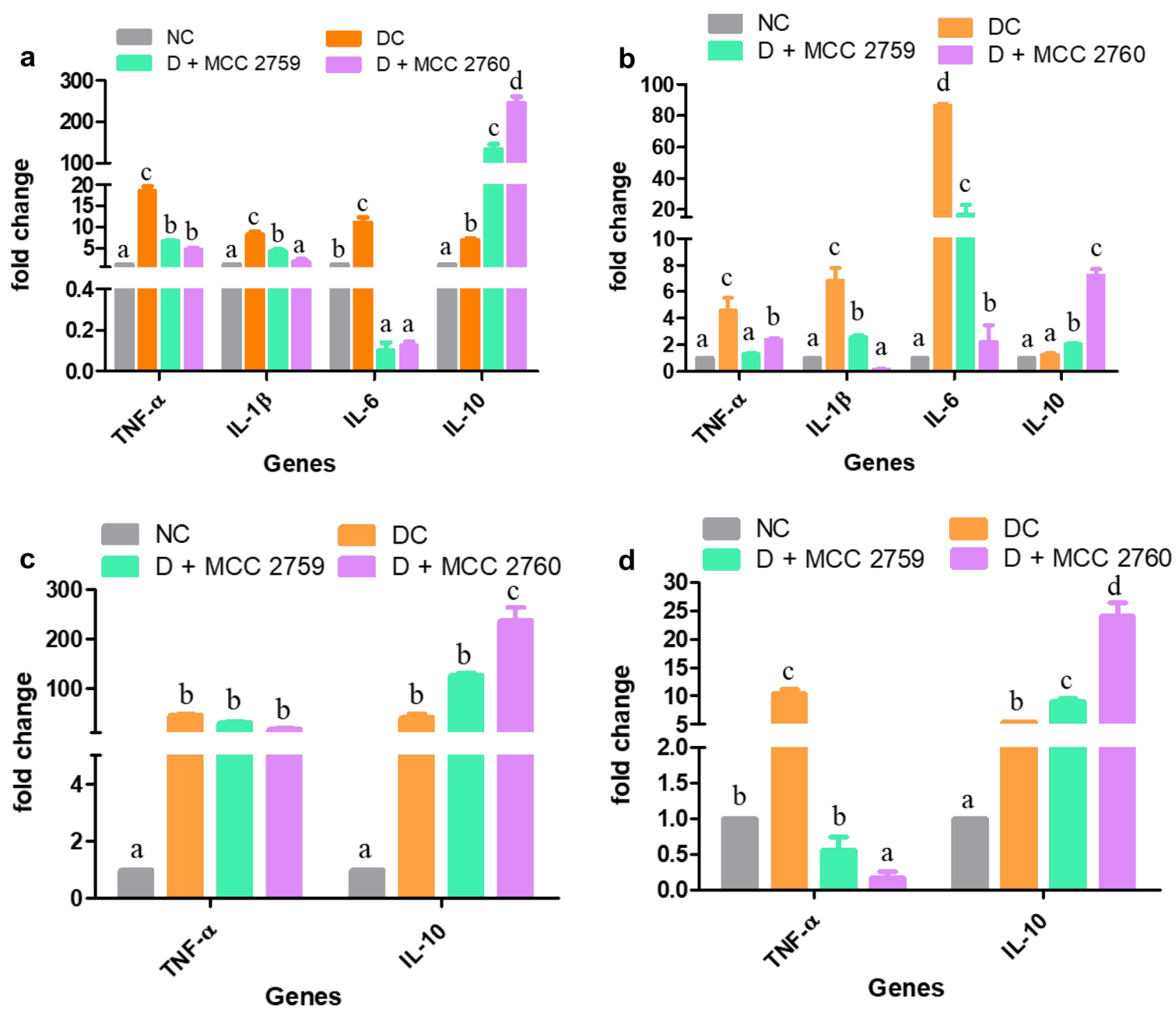

Fig. 3 Expression changes in inflammatory markers of different diabetic study groups monitored by qPCR: a intestine, b liver, c MAT and $\mathbf{d}$ muscle tissue. Data presented as mean $\pm \operatorname{SEM}(n=6)$. Letters

with different superscripts are significant at $p<0.001$. The mRNA expression was normalized to GAPDH. NC normal control, DC diabetic control, D diabetic, MCC2759 and MCC2760 L. fermentum spp

and initiate a low-grade inflammatory tone in important organs of the body making the host highly susceptible to attaining type 2 diabetes. Conversely, HFD coupled with a low dose of STZ is said to mimic the metabolic characteristics of type 2 diabetes and is a novel model for anti-diabetic studies [12].

High-fat or high-cholesterol diet contributes to an increase in body weight. Few studies have reported the weight-lowering ability of lactic acid bacteria (LAB) in such models. Certain strains of LAB have shown the ability to prevent body weight gain $[16,17]$. Increased excretion of bile acids in the faeces may increase bile acid synthesis and induce energy expenditure contributing to weight loss. In study 1 , due to HFD feeding, the control

groups gained a significant amount of weight throughout the 8 weeks. However, the weight gain and food intake were significantly controlled in groups that received Lact. fermentum MCC2759 and MCC2760 from the 5th week. STZ-induced diabetes typically presents severe loss of body weight due to degeneration of structural proteins that are crucial for body weight $[12,18]$. There was no significant increase in the bodyweight of Lact. fermentum treated groups compared with the diabetic control group in study 1 implying the effects of STZ. Reduced body weight also corresponded to the reduced organ weight in study 2 groups. In correlation with body weight, serum biochemical markers such as glucose, triglycerides, and cholesterol were improved in Lact. fermentum treated groups in both studies. Similar 

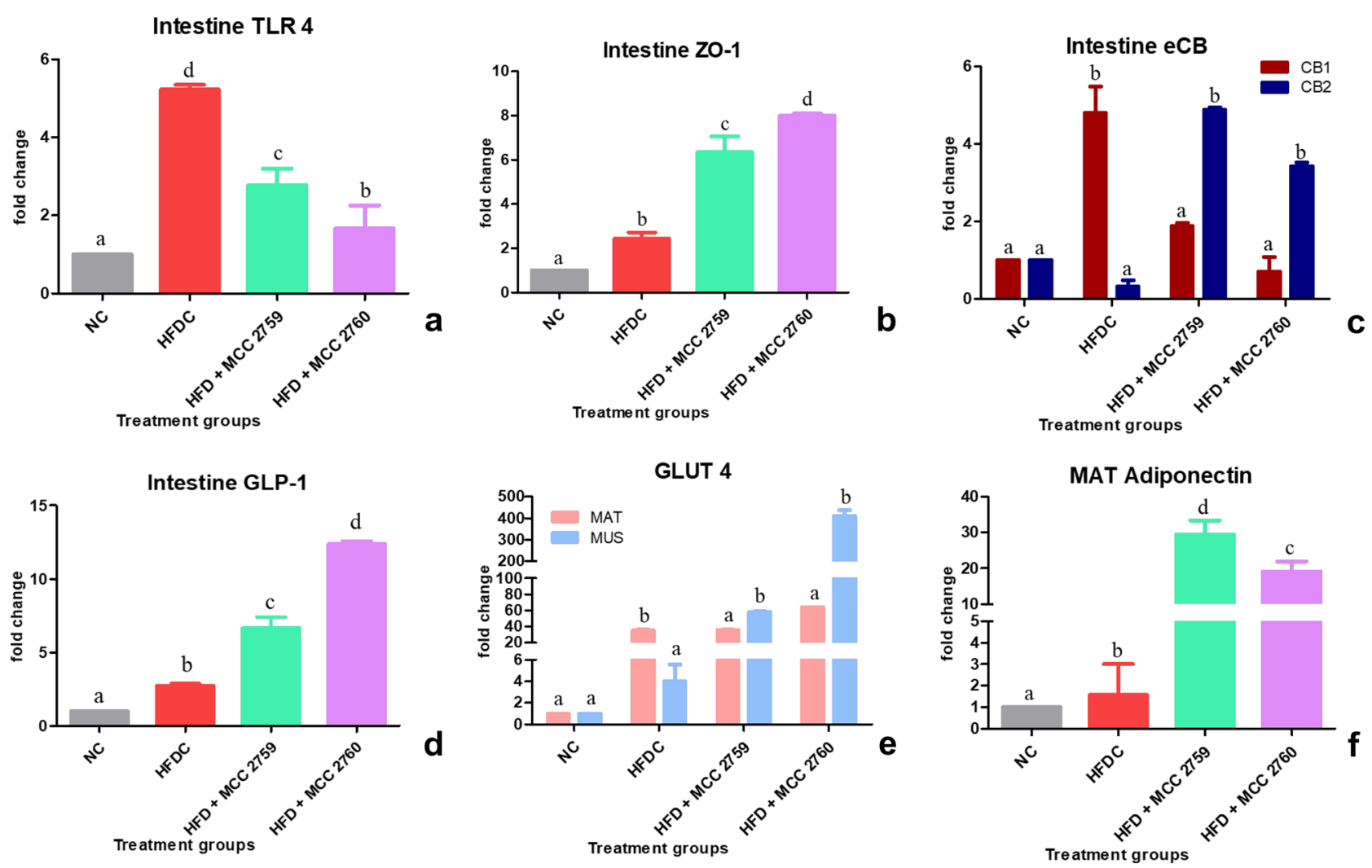

Fig. 4 Expression changes in intestinal and other markers in highfat diet fed study groups monitored by qPCR: a TLR4, b ZO-1, c eCB system, d GLP1 intestinal markers, e GLUT4 expression levels in mesenteric adipose tissue and muscle tissue and $\mathbf{f}$ adiponectin expression levels in mesenteric adipose tissue. Data presented as

positive effects of probiotics on serum markers were also found in other studies [19-21]. Some strains of probiotics are known to reduce serum cholesterol levels by increasing the excretion of bile acids in faeces and affecting cholesterol synthesis pathways [22, 23].

Obesity and diabetes are metabolic disorders characterized by a low-grade inflammatory condition [6]. TNF- $\alpha$ is a pro-inflammatory cytokine which under elevated conditions is known to phosphorylate serine residue substrate (IRS-1) on the insulin receptor causing its inactivation, while IL- $1 \beta$, TNF- $\alpha$, and IFN- $\gamma$ are known to act synergistically by infiltrating the pancreas and inducing $\beta$-cell damage and apoptosis [24]. Overall the raised levels of these pro-inflammatory cytokines in hepatocytes, muscle, and adipose tissue play a major role in the pathology of diabetes by interfering with insulin signalling and inducing insulin resistance. However, supplementation of Lact. fermentum showed downregulation of these genes in the intestine, liver, MAT, and muscle mainly by stimulating the expression of anti-inflammatory regulatory cytokine IL-10 suggesting its immunomodulatory potential. Lactobacillus casei strain Shirota showed a significant reduction in the mean \pm SEM $(n=6)$. Letters with different superscripts are significant at $p<0.001$. The mRNA expression was normalized to GAPDH. NC normal control, HFDC-high-fat diet control, HFD high-fat diet, MCC2759 and MCC2760 L. fermentum spp., MAT mesenteric adipose tissue, MUS muscle

levels of pro-inflammatory cytokines IL-6, IL-4, and C-reactive protein in STZ-induced diabetic rats [25]. Probiotic mixture VSL\#3 was found to reduce the levels of TNF- $\alpha$ and concomitantly augment IL-10 in a diabetic mice model fed for 12 weeks [26]. Similar studies have shown the effects of probiotic lactobacilli on inflammatory markers [20,27]. Our findings are consistent with previous reports suggesting the anti-inflammatory potential of Lact. fermentum spp.

Microbial detection in the intestine occurs by recognition of pathogen-associated molecular patterns (PAMPs) such as LPS by specialized receptors called TLRs present on the cell surface that trigger the immune response [28]. Constant levels of LPS in the gut trigger an inflammatory response via the TLR4. In both models, the expression of TLR4 was found to be down-regulated by Lact. fermentum treatment suggestive of its ability to modulate gut microbiota and control the levels of LPS generated. The eCB system is also thought to modulate intestinal permeability by enhancing the distribution and localization of tight junction proteins [29]. In our study, Lact. fermentum displayed the ability to influence the eCB system by down-regulating the expression of CB1 

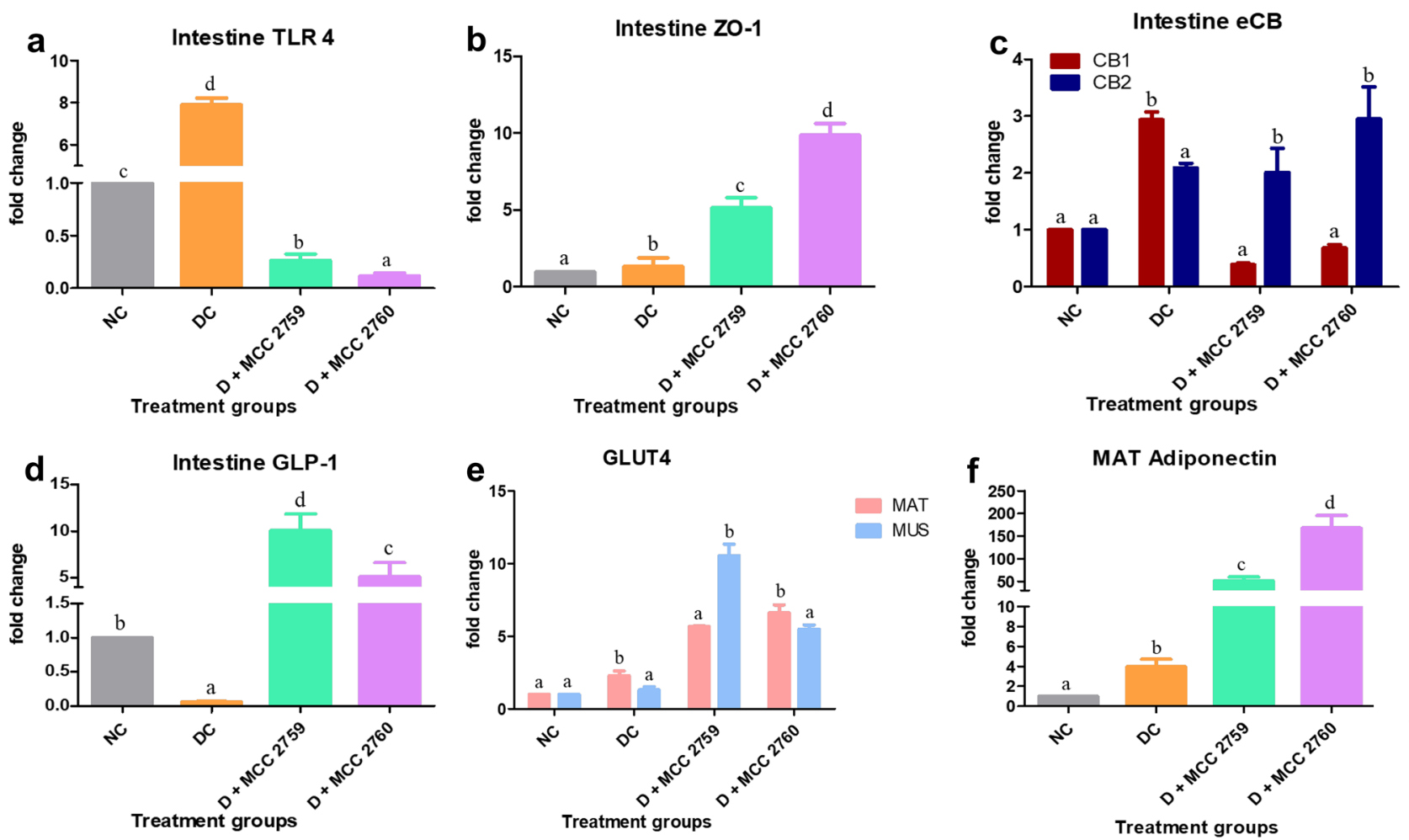

Fig. 5 Expression changes in intestinal and other markers in diabetic study groups monitored by qPCR: a TLR4, b ZO-1, c eCB system, d GLP1 intestinal markers, e GLUT4 expression levels in mesenteric adipose tissue and muscle tissue and $\mathbf{f}$ adiponectin expression levels in mesenteric adipose tissue. Data presented as mean $\pm \operatorname{SEM}(n=6)$.
Letters with different superscripts are significant at $p<0.001$. The mRNA expression was normalized to GAPDH. NC normal control, DC diabetic control, D diabetic, MCC2759 and MCC2760 L. fermentum spp., MAT mesenteric adipose tissue, MUS muscle

the enhanced ZO-1 expression by L. fermentum treatment. Species of Lactobacillus, namely Lact. acidophilus, Lact. rhamnosus, Lact. gasseri, and Lact. fermentum, is known
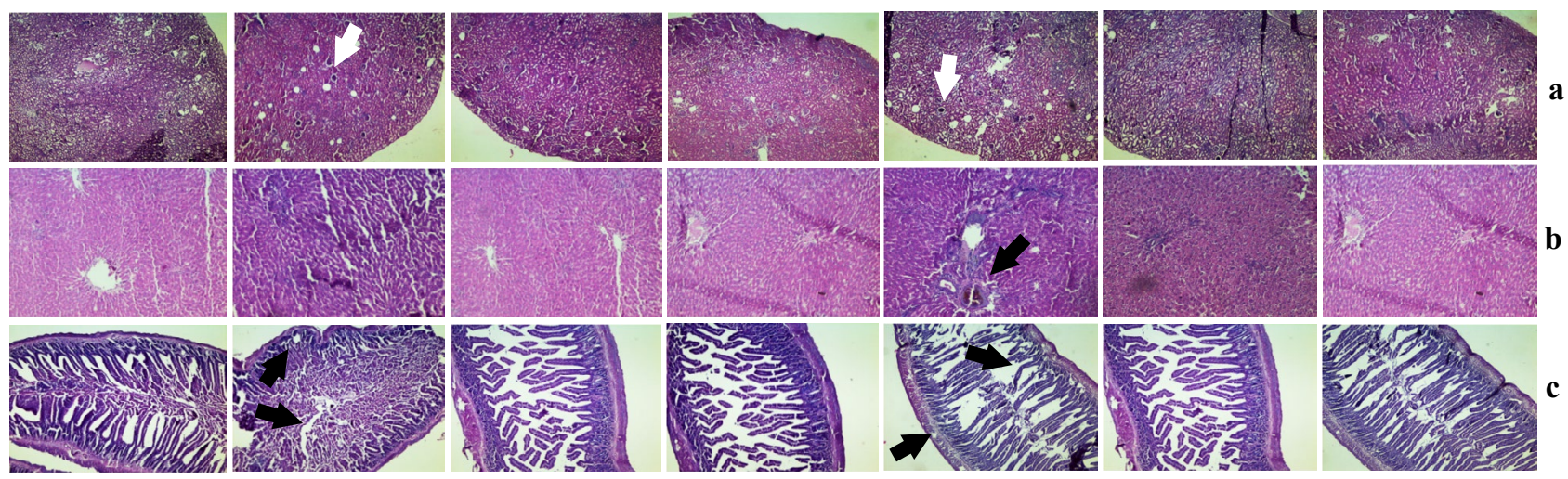

Normal

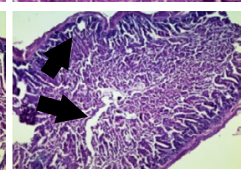

Diabetic control

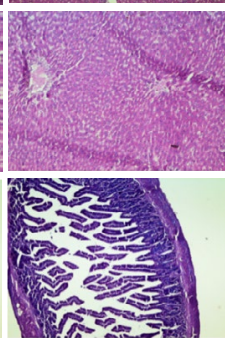

$\mathrm{D}+\mathrm{MCC} 2760$

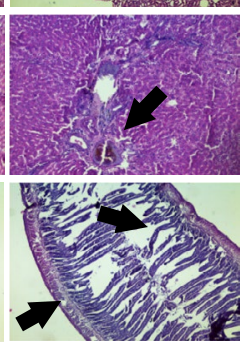

High fat diet

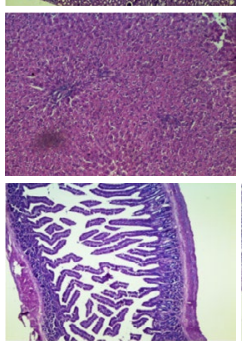

HFD + MCC2759

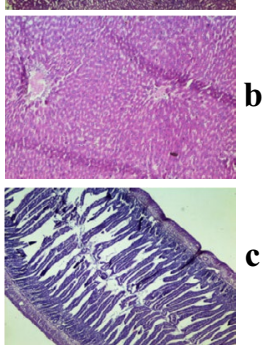

HFD + MCC2760
Fig. 6 Histopathological indications of control and Lact. fermentum treated groups in diabetic and high-fat diet fed study. a Liver tissue-arrow indicates neutrophil infiltration; b kidney tissue-arrows indicate darkened glomeruli; c intestine-arrows indicate irregular crypts, damage of epithelial surface and shedding of the smooth mus- cle lining; hematoxylin and eosin staining at $\times 40$ magnification; $\mathrm{NC}$ normal control, DC diabetic control, D diabetic, HFDC high-fat diet control, HFD high-fat diet, MCC2759 and MCC2760 L. fermentum spp 
to influence the expression of tight junction proteins [30]. Supplementation of Lact. fermentum augmented the expression of GLP-1 in the intestine which seems to play a role in improving inflammation and insulin resistance caused by high-fat diet intake [6]. Probiotics are known to influence the secretion of GLUT4, thereby facilitating glucose uptake and reduction of insulin resistance in adipose and muscle tissue [31]. Kim et al. [32] showed that Lact. rhamnosus GG stimulated GLUT4 expression in muscle tissue of high-fat diet-fed mice. In our study, Lact. fermentum supplementation also positively influenced the expression of GLUT4 in MAT and muscle tissue correlating with previous reports. Lact. fermentum administration to the diabetic and high-fat dietfed rats resulted in higher expression of adiponectin levels probably due to the reduction of pro-inflammatory response in adipose tissue and enhancement of GLUT4 [32]. Adiponectin levels are said to be low in obese subjects [33]. Probiotic therapy may help in augmenting their levels by stimulating GLUT4 and reducing inflammation in adipose tissue.

Insulin resistance in the cells of different tissues is marked by the cellular infiltration of inflammatory molecules due to enhanced secretion of pro-inflammatory cytokines. Infiltration of neutrophils indicates inflammation of the tissues as evident by qPCR results which showed increased expression of proinflammatory cytokines. Lact. fermentum administration in both studies exhibited reduced neutrophil infiltration as seen in histopathological observations. Oral administration of Lact. reuteri improved hepatic steatosis and insulin resistance in liver tissues of high fructose-fed rats [34]. These findings indicate that inflammation and steatosis caused due to the consumption of a high-fat diet may be ameliorated by the administration of Lact. fermentum. Consumption of a highfat diet causes dysbiosis of the intestinal mucosal milieu compromising the integrity of the mucosal barrier. Lact. fermentum treated groups showed improved mucosal lining and barrier integrity structure compared with the control. Darkened and diffused sections of Bowman's capsule in the kidney indicate macrophage infiltration as previously observed by Sharavana et al. [35], which normalized upon Lact. fermentum treatment in our study.

In conclusion, this study demonstrated the beneficial role of Lact. fermentum spp. principally through its anti-inflammatory and potential probiotic action in models of HFD feeding and STZ-induced diabetes. Lact. fermentum MCC2759 and MCC2760 exhibited beneficial effects in HFD and type 2 diabetic models by improving glucose and lipid profile, reduction of pro-inflammatory cytokines in liver, intestine, MAT, and muscle tissue, and improving the intestinal barrier function and expression of GLUT4, GLP1, and adiponectin. Lact. fermentum MCC2760 showed slightly better effects compared with MCC2759. The cultures could act as promising candidates for inflammatory conditions as they show an overall reduction of inflammation in various tissues and organs of the body. Count of pathogenic bacteria like Escherichia coli, Staphylococcus aureus, and Campylobacter spp. appeared to be reduced in faeces of Lact. fermentum treated groups of both studies as obtained by plate count (data not shown). However, further studies and human trials are required to validate their effects.

\section{Data Availability}

The datasets generated during and/or analysed during the current study are available from the corresponding author on reasonable request.

Supplementary Information The online version contains supplementary material available at https://doi.org/10.1007/s12602-021-09744-0.

Acknowledgements The authors wish to express their sincere thanks to Director, CSIR-CFTRI, Mysuru, for providing the necessary facilities.

Authors' Contributions All authors contributed to the study conception and design. Material preparation, data collection, and analysis were performed by Ann Catherine Archer. The first draft of the manuscript was written by Ann Catherine Archer, and all authors commented on previous versions of the manuscript. All authors read and approved the final manuscript.

Funding The research leading to these results received funding from Indian Council of Medical Research (ICMR) under Grant Agreement No. 5/7/508/10-RHN. ACA received grant from Maulana Azad National Fellowship by University Grants Commission (UGC), New Delhi, India.

\section{Compliance with Ethical Standards}

Competing Interests The authors declare that they have no conflict of interest.

Ethics Approval All procedures performed in studies involving human participants were in accordance with guidelines of Committee for the Purpose of Control and Supervision of Experiments on Animals (CPCSEA), Government of India and approved by the Institute Animal Ethical Committee (IAEC), CSIR-CFTRI, Mysuru, in accordance with IAEC regulations (approval no. 335/14).

Open Access This article is licensed under a Creative Commons Attribution 4.0 International License, which permits use, sharing, adaptation, distribution and reproduction in any medium or format, as long as you give appropriate credit to the original author(s) and the source, provide a link to the Creative Commons licence, and indicate if changes were made. The images or other third party material in this article are included in the article's Creative Commons licence, unless indicated otherwise in a credit line to the material. If material is not included in the article's Creative Commons licence and your intended use is not permitted by statutory regulation or exceeds the permitted use, you will need to obtain permission directly from the copyright holder. To view a copy of this licence, visit http://creativecommons.org/licenses/by/4.0/. 


\section{References}

1. Gomes AC, Bueno AA, de Souza RGM, Mota JF (2014) Gut microbiota, probiotics and diabetes. Nutr J 13:60. https://doi. org/10.1186/1475-2891-13-60

2. Guariguata L, Whiting DR, Hambleton I, Beagley J, Linnenkamp U, Shaw JE (2014) Global estimates of diabetes prevalence for 2013 and projections for 2035. Diabetes Res Clin Pract 103:137149. https://doi.org/10.1016/j.diabres.2013.11.002

3. Amar J, Chabo C, Waget A, Klopp P, Vachoux C, BermúdezHumarán LG, Smirnova N, Bergé M, Sulpice T, Lahtinen S, Ouwehand A (2011) Intestinal mucosal adherence and translocation of commensal bacteria at the early onset of type 2 diabetes: molecular mechanisms and probiotic treatment. EMBO Mol Med 3:559-572. https://doi.org/10.1002/emmm.201100159

4. Tanti JF, Gual P, Gremeaux T, Gonzalez T, Barres R, Le Marchand-Brustel Y (2004) Alteration in insulin action: role of IRS-1 serine phosphorylation in the retroregulation of insulin signalling. In Annales d'endocrinologie 65(1): 43-48. Elsevier Masson. https://doi.org/10.1016/S0003-4266(04)95629-6

5. Holmes E, Li JV, Athanasiou T, Ashrafian H, Nicholson JK (2011) Understanding the role of gut microbiomehost metabolic signal disruption in health and disease. Trends Microbiol 19:349-359. https://doi.org/10.1016/j. tim.2011.05.006

6. Cani PD, Delzenne NM, Amar J, Burcelin R (2008) Role of gut microflora in the development of obesity and insulin resistance following high-fat diet feeding. Pathol Biol (Paris) 56:305-309. https://doi.org/10.1016/j.patbio.2007.09.008

7. Larsen N, Vogensen FK, Van Den Berg FW, Nielsen DS, Andreasen AS, Pedersen BK, Al-Soud WA, Sørensen SJ, Hansen LH, Jakobsen M (2010) Gut microbiota in human adults with type 2 diabetes differs from non-diabetic adults. PLoS ONE 5:e9085. https://doi.org/10.1371/journal.pone.0009085

8. Vrieze A, Van Nood E, Holleman F, Salojärvi J, Kootte RS, Bartelsman JF, Dallinga-Thie GM, Ackermans MT, Serlie MJ, Oozeer R, Derrien M (2012) Transfer of intestinal microbiota from lean donors increases insulin sensitivity in individuals with metabolic syndrome. Gastroenterol 143:913-916. https:// doi.org/10.1053/j.gastro.2012.06.031

9. He M, Shi B (2017) Gut microbiota as a potential target of metabolic syndrome: the role of probiotics and prebiotics. Cell Biosci 7:1-14. https://doi.org/10.1186/s13578-017-0183-1

10. Hsu CL, Hou YH, Wang CS, Lin SW, Jhou BY, Chen CC, Chen YL (2019) Antiobesity and uric acid-lowering effect of Lactobacillus plantarum GKM3 in high-fat-diet-induced obese rats. J Am Coll Nutr 38:623-632. https://doi.org/10.1080/ 07315724.2019.1571454

11. Michael DR, Jack AA, Masetti G, Davies TS, Loxley KE, Kerry-Smith J, Plummer JF, Marchesi JR, Mullish BH, McDonald JAK, Hughes TR (2020) A randomised controlled study shows supplementation of overweight and obese adults with lactobacilli and bifidobacteria reduces bodyweight and improves well-being. Sci Rep 10:1-12. https://doi.org/10.1038/ s41598-020-60991-7

12. Srinivasan K, Viswanad B, Asrat L, Kaul CL, Ramarao P (2005) Combination of high-fat diet-fed and low-dose streptozotocintreated rat: a model for type 2 diabetes and pharmacological screening. Pharmacol Res 52:313-320. https://doi.org/10.1016/j. phrs.2005.05.004

13. Archer AC, Halami PM (2015) Probiotic attributes of Lactobacillus fermentum isolated from human feces and dairy products. Appl Microbiol Biotechnol 99:8113-8123. https://doi. org/10.1007/s00253-015-6679-x
14. Archer AC, Muthukumar SP, Halami PM (2015) Antiinflammatory potential of probiotic Lactobacillus spp. on carrageenan induced paw edema in Wistar rats. Int $\mathbf{J}$ Biol Macromol 81:530-537. https://doi.org/10.1016/j.ijbiomac. 2015.08.044

15. Archer AC, Kurrey NK, Halami PM (2018) In vitro adhesion and anti-inflammatory properties of native Lactobacillus fermentum and Lactobacillus delbrueckii spp. J Appl Microbiol 125:243-256. https://doi.org/10.1111/jam.13757

16. Kang JH, Yun SI, Park HO (2010) Effects of Lactobacillus gasseri BNR17 on body weight and adipose tissue mass in diet-induced overweight rats. J Microbiol 48:712-714. https://doi.org/10.1007/ s12275-010-0363-8

17. Sanchez M, Darimont C, Drapeau V, Emady-Azar S, Lepage M, Rezzonico E, Ngom-Bru C, Berger B, Philippe L, AmmonZuffrey C, Leone P (2014) Effect of Lactobacillus rhamnosus CGMCC1. 3724 supplementation on weight loss and maintenance in obese men and women. Brit J Nutr 111:1507-1519. https://doi. org/10.1017/S0007114513003875

18. Singh S, Sharma RK, Malhotra S, Pothuraju R, Shandilya UK (2014) Assessment of gut associated changes and adipose tissue inflammation in high fat diet fed Streptozotocin-induced diabetic rats. J Innov Biol 1:068-077. 10.1.1.679.4353

19. Li X, Wang N, Yin B, Fang D, Jiang T, Fang S, Zhao J, Zhang H, Wang G, Chen W (2016) Effects of Lactobacillus plantarum CCFM0236 on hyperglycaemia and insulin resistance in high-fat and streptozotocin-induced type 2 diabetic mice. J Appl Microbiol 121:1727-1736. https://doi.org/10.1111/jam.13276

20. Singh S, Sharma RK, Malhotra S, Pothuraju R, Shandilya UK (2017) Lactobacillus rhamnosus NCDC17 ameliorates type-2 diabetes by improving gut function, oxidative stress and inflammation in high-fat-diet fed and streptozotocin treated rats. Benef Microbes 8:243-255. https://doi.org/10.3920/BM2016. 0090

21. Yadav R, Dey DK, Vij R, Meena S, Kapila R, Kapila S (2018) Evaluation of anti-diabetic attributes of Lactobacillus rhamnosus MTCC: 5957, Lactobacillus rhamnosus MTCC: 5897 and Lactobacillus fermentum MTCC: 5898 in streptozotocin induced diabetic rats. Microb Pathog 125:454-462. https://doi. org/10.1016/j.micpath.2018.10.015

22. Costabile A, Buttarazzi I, Kolida S, Quercia S, Baldini J, Swann JR, Brigidi P, Gibson GR (2017) An in vivo assessment of the cholesterol-lowering efficacy of Lactobacillus plantarum ECGC 13110402 in normal to mildly hypercholesterolaemic adults. PLoS ONE 12:e0187964. https://doi.org/10.1371/journal.pone.0187964

23. Park S, Kang J, Choi S, Park H, Hwang E, Kang Y, Kim A, Holzapfel W, Ji Y (2018) Cholesterol-lowering effect of Lactobacillus rhamnosus BFE5264 and its influence on the gut microbiome and propionate level in a murine model. PLoS ONE 13:e0203150. https://doi.org/10.1371/journal.pone.0203150

24. Alexandraki K, Piperi C, Kalofoutis C, Singh J, Alaveras A, Kalofoutis A (2006) Inflammatory process in type 2 diabetes: the role of cytokines. Ann N Y Acad Sci 1084:89-117. https://doi. org/10.1196/annals.1372.039

25. Zarfeshani A, Khaza'ai H, Ali RM, Hambali Z, Wahle KWJ, Mutalib MSA (2011) Effect of Lactobacillus casei on the production of pro-inflammatory markers in streptozotocin-induced diabetic rats. Probiotics Antimicrob Proteins 3:168-174. https:// doi.org/10.1007/s12602-011-9080-9

26. Mencarelli A, Cipriani S, Renga B, Bruno A, D'Amore C, Distrutti E, Fiorucci S (2012) VSL\# 3 resets insulin signaling and protects against NASH and atherosclerosis in a model of genetic dyslipidemia and intestinal inflammation. PloS One 7:p.e45425. https://doi.org/10.1371/journal.pone.0045425 
27. Liu Y, Gao Y, Ma F, Sun M, Mu G, Tuo Y (2020) The ameliorative effect of Lactobacillus plantarum Y44 oral administration on inflammation and lipid metabolism in obese mice fed by high fat diet. Food Funct 11:5024-5039. https://doi.org/10.1039/ D0FO00439A

28. Kufer TA, Sansonetti PJ (2011) NLR functions beyond pathogen recognition. Nat Immunol 12:121-128. https://doi.org/10.1038/ ni. 1985

29. Cani PD, Osto M, Geurts L, Everard A (2012) Involvement of gut microbiota in the development of low-grade inflammation and type 2 diabetes associated with obesity. Gut Microbes 3:279-288. https://doi.org/10.4161/gmic. 19625

30. Hummel S, Veltman K, Cichon C, Sonnenborn U, Schmidt MA (2012) Differential targeting of the E-cadherin/ $\beta$-catenin complex by Gram-positive probiotic lactobacilli improves epithelial barrier function. Appl Environ Microbiol 78:1140-1147. https://doi. org/10.1128/AEM.06983-11

31. Herman MA, Kahn BB (2006) Glucose transport and sensing in the maintenance of glucose homeostasis and metabolic harmony. J Clin Investig 116:1767-1775. https://doi.org/10.1172/JCI29027
32. Kim SW, Park KY, Kim B, Kim E, Hyun CK (2013) Lactobacillus rhamnosus $\mathrm{GG}$ improves insulin sensitivity and reduces adiposity in high-fat diet-fed mice through enhancement of adiponectin production. Biochem Biophys Res Comm 431:258-263. https:// doi.org/10.1016/j.bbrc.2012.12.121

33. Lihn AS, Pedersen SB, Richelsen B (2005) Adiponectin: action, regulation and association to insulin sensitivity. Obes Rev 6:1321. https://doi.org/10.1111/j.1467-789X.2005.00159.x

34. Hsieh FC, Lee CL, Chai CY, Chen WT, Lu YC, Wu CS (2013) Oral administration of Lactobacillus reuteri GMNL-263 improves insulin resistance and ameliorates hepatic steatosis in high fructose-fed rats. Nutr Metabol 10:35. https://doi.org/10.1186/1743-7075-10-35

35. Sharavana G, Joseph GS, Baskaran V (2017) Lutein attenuates oxidative stress markers and ameliorates glucose homeostasis through polyol pathway in heart and kidney of STZ-induced hyperglycemic rat model. Eur J Nutr 56(8):2475-2485. https:// doi.org/10.1007/s00394-016-1283-0

Publisher's Note Springer Nature remains neutral with regard to jurisdictional claims in published maps and institutional affiliations. 